\title{
Adhesion of coagulase-negative staphylococci grouped according to physico-chemical surface properties
}

\author{
Henny C. van der Mei, ${ }^{1}$ Betsy van de Belt-Gritter, ${ }^{1}$ Gregor Reid, ${ }^{2,3}$ \\ Hanna Bialkowska-Hobrzanska ${ }^{3}$ and Henk J. Busscher ${ }^{1,2}$
}

Author for correspondence: Henny C. van der Mei. Tel: +3150 3633140. Fax: +31503633159.

e-mail: h.c.van.der.mei@med.rug.nl

1 Laboratory for Materia Technica, University of Groningen, Bloemsingel 10, 9712 KZ Groningen, The Netherlands

2 Department of Microbiology and Immunology, University of Western Ontario, Health Sciences Centre, London, Ontario, Canada N6A 5C1

3 Lawson Research Institute, 268 Grosvenor Street, London, Ontario, Canada N6A 4V2
Physico-chemical cell surface properties of 23 coagulase-negative staphylococcal strains, including contact angles, zeta potentials and elemental cell surface composition were measured, together with the adhesion of all strains to hexadecane. The data were employed in a hierarchical cluster analysis, revealing that the $\mathbf{2 3}$ strains comprised essentially four different groups. Groups I-III were somewhat similar to each other, but group IV was markedly distinguished from the other strains, predominantly through an elevated acidity of the cell surface. These group distinctions were not related to the presence of a capsule or slime on the strains. Adhesion of the strains to hexadecane depended critically on electrostatic interactions between the hexadecane and the staphylococci, and adhesion only occurred when the electrostatic repulsion between hexadecane and the micro-organisms was less than $\mathbf{5 0 0} \mathrm{kT}$ at closest approach. Adhesion of six representative strains from all four groups in a parallel plate flow chamber to silicone rubber, an implant material with similar hydrophobicity to hexadecane, did not show such a critical dependence, nor did it relate with the group distinction. Possibly, microbial adhesion to substratum surfaces like silicone rubber is more complicated than adhesion to an ideally smooth and homogeneous hexadecane surface in an aqueous solution. Adhesion of all six strains to silicone rubber with an adsorbed conditioning film of plasma proteins was less than that to bare silicone rubber: initial deposition rates dropped from $2000-3000 \mathrm{~cm}^{-2} \mathrm{~s}^{-1}$ to $100-300 \mathrm{~cm}^{-2} \mathrm{~s}^{-1}$ after adsorption of plasma proteins, while the stationary end-point adhesion decreased from $10 \times 10^{6}-15 \times 10^{6} \mathrm{~cm}^{-2}$ to $1 \times 10^{6}-5 \times 10^{6} \mathrm{~cm}^{-2}$. The adhering staphylococci poorly withstood the passage of an air-bubble through the parallel plate flow chamber, regardless of the presence of a conditioning film, indicating a low affinity of these relatively hydrophilic strains for hydrophobic substratum surfaces.

Keywords: silicone rubber, plasma proteins, zeta potentials, hydrophobicity

\section{INTRODUCTION}

Adhesion of coagulase-negative staphylococci (CNS) is a major cause of infections associated with implants and medical devices, such as prosthetic heart valves, pacemakers, vascular grafts and invasive vascular catheters, cerebrospinal fluid shunts, orthopaedic implants, urinary tract and suprapubic catheters, peritoneal dialysis

Abbreviations: CNS, coagulase-negative staphylococci; MATH, microbial adhesion to hydrocarbons; XPS, X-ray photoelectron spectroscopy. catheters and mammary prostheses (Hogt et al., 1983). Understanding the mechanisms of adhesion utilized by CNS to implantable medical device surfaces is pivotal to the prevention of infection, especially since established CNS biofilms are hard to eradicate with antibiotic treatment (Lee et al., 1995).

No single mechanism will probably ever be identified as being solely responsible for adhesion of CNS or other microbial strains to surfaces (Busscher et al., 1992). A physico-chemical approach, however, has been successfully applied to explain, for example, why hydro- 
phobic streptococci and Candida species adhere in higher numbers to hydrophobic surfaces and why their rate of adhesion is highest in the absence of strong electrostatic repulsion (Busscher et al., 1997). In addition, analysis of the physico-chemical forces involved in microbial adhesion to hydrocarbons (MATH) (Rosenberg et al., 1980) has demonstrated that MATH is strictly regarded not as an assay probing microbial cell surface hydrophobicity as is frequently assumed, but rather as an assay probing adhesion of micro-organisms to a negatively charged, hydrophobic substratum, i.e. the hydrocarbon phase (Busscher et al., 1995; Van der Mei et al., 1995). Hydrophilic micro-organisms do not adhere to the hydrocarbon phase regardless of the absence or presence of electrostatic repulsion (Van der Mei et al., 1993), while hydrophobic cells only adhere to the hydrocarbon phase when electrostatic repulsion is moderate or absent (Geertsema-Doornbusch et al., 1993). These observations on the mechanisms of MATH justify that water contact angle measurements on microbial lawns have been suggested to be the only assay available to probe the so-called intrinsic microbial cell surface hydrophobicity (Van der Mei et al., 1995; Busscher et al., 1995), although this is not yet universally accepted.

Some work has been done on the influence of substratum physico-chemical surface chemistry on adhesion of CNS (Gilbert et al., 1991), but few studies have given a thorough description of the physico-chemical properties of CNS cell surfaces and their impact on adhesion. For instance, it has been suggested that certain plasmids of CNS transfer cell surface hydrophobicity (Busscher et al., 1994) but that study only comprised four strains. Also staphylococci have been distinguished from oral streptococci on the basis of physico-chemical cell surface properties (Van der Mei et al., 1989) but with no obvious connection to their adhesion to implant or medicaldevice surfaces.

Silicone rubber is frequently used for medical devices and it is prone to becoming colonized by CNS (Boswald et al., 1995). When used for application as a bloodcontacting implant or device, the silicone rubber first adsorbs a layer of plasma proteins often called 'conditioning film' prior to adhesion of CNS (Gristina et al., 1988; Ziats et al., 1990). The composition of the conditioning film as well as the conformation of adsorbed proteins is dictated by the wettability of the implant or device surface. For instance, hydrophobic biomaterials are known to adsorb albumin-rich conditioning films, whereas on hydrophilic biomaterials adsorbed albumin gets replaced over time with fibrinogen, immunoglobulin $G$ and other high molecular mass components (Vroman \& Adams, 1985; Elwing et al., 1987). In general, it is believed that adsorbed fibrinogen stimulates adhesion of Stapbylococcus aureus (Zdanowski et al., 1993; Cheung et al., 1991), provided it is adsorbed in a conformational state leaving possible acceptor sites available for staphylococci to adhere to.

The aim of this study was to make an inventory of physico-chemical cell surface properties of 23 clinical
CNS isolates and to prepare a grouping of the isolates according to these properties, including their adhesion to hexadecane. Also, relationships were sought between the various cell surface properties measured. Subsequently, on the basis of the grouping obtained, adhesion of CNS isolates from distinct groups to silicone rubber was studied in a parallel plate flow chamber with and without a conditioning film of adsorbed plasma proteins in an attempt to explain adhesion of CNS to these surfaces on a physico-chemical basis.

\section{METHODS}

Strains and growth conditions. The 23 Staphylococcus epidermidis strains used in this study are listed in Table 1, together with their code number which is used throughout the paper. The strains involved were isolated from the skin, stool, blood and urinary tract and comprise two ATCC strains. The strains were cultured in Trypticase soy broth (Oxoid) for $24 \mathrm{~h}$ at $37^{\circ} \mathrm{C}$ from a frozen stock kept at $-60^{\circ} \mathrm{C}$. This culture was used to inoculate a second culture which was grown for $16 \mathrm{~h}$.

For physico-chemical surface characterization, bacteria were harvested after growth by centrifugation at $5000 \mathrm{~g}$ for $10 \mathrm{~min}$ and washed twice with demineralized water. The bacterial pellets were then either deposited on a filter for contact angle measurements, resuspended in $10 \mathrm{mM}$ potassium phosphate buffer for adhesion to hexadecane and microelectrophoresis, or freeze-dried for XPS. For adhesion experiments in the flow chamber, bacteria were resuspended in PBS $(10 \mathrm{mM}$ potassium phosphate, $150 \mathrm{mM}$ sodium chloride, $\mathrm{pH} 7 \cdot 0$ ).

Molecular typing. RFLP analysis of whole chromosomal DNA using ClaI was conducted as described previously (Bialkowska-Hobrzanska et al., 1990b). rDNA RFLP analysis consisted of DNA restriction with ClaI, separation of the fragments on agarose gels, transfer of the fragments to a membrane and hybridization with ${ }^{32} \mathrm{P}$-labelled $16 \mathrm{~S}+23 \mathrm{~S}$ rRNA from Escherichia coli as reported previously (Bialkowska-Hobrzanska et al., 1990a). DNA patterns were scanned with a laser densitometer (Ultroscan XL model 2222, Pharmacia-LKB) and their genetic similarities were assessed using a computer program as described previously (Bialkowska-Hobrzanska et al., 1990b). The criteria for the identity of isolates were based on the relatedness of chromosomal DNA banding patterns. A numerical system has been introduced to describe genetic identity of individual isolates (Bialkowska-Hobrzanska et al., 1993). Isolates with more than $95 \%$ DNA banding similarity were considered identical strains and were described by three identical numerals, e.g. 5.2.1 and 5.2.1. Those with 85-95\% similar bands were considered related strains; they were described by two identical numerals, e.g. 5.2.1 and 5.2.2. The isolates with less than $85 \%$ but more than $60 \%$ similarity were considered distinct strains, e.g. 5.6.1 and 5.1.1.

Slime and capsule production test. Slime production was tested as described by Christensen et al. (1982). Capsule production was determined using the India Ink method after growing $S$. epidermidis isolated on blood agar plates and passing the cells through Luria broth containing serum (Matthews et al., 1991). Slides were examined by phase contrast microscopy.

Microbial cell surface characterization. The zeta potentials of the staphylococci were measured as described previously (Van der Mei et al., 1989). Briefly, each bacterial strain was resuspended in $50 \mathrm{ml} 10 \mathrm{mM}$ potassium phosphate solution, 
Table 1. Contact angles $\left(^{\circ}\right)$ of water $\left(\theta_{\mathrm{H}_{2} \mathrm{O}}\right)$, formamide $\left(\theta_{\mathrm{F}}\right)$, methyleneiodide $\left(\theta_{\mathrm{D}}\right)$ and $\alpha$-bromonaphthalene $\left(\theta_{\alpha \mathrm{B}}\right)$ measured on lawns of staphylococci

An indication of the acidity of the staphylococcal cell surfaces, based on the ratio between the surface free energy parameters $\gamma^{+}$ (hydrogen-donating) and $\gamma^{-}$(electron-donating) (Van Oss et al., 1986) is given, together with genetic characteristics, production of a capsule or slime and source. The SD in the contact angles over three separately grown cultures of each strain amounted to a mean of $4^{\circ}$. NT, Not tested.

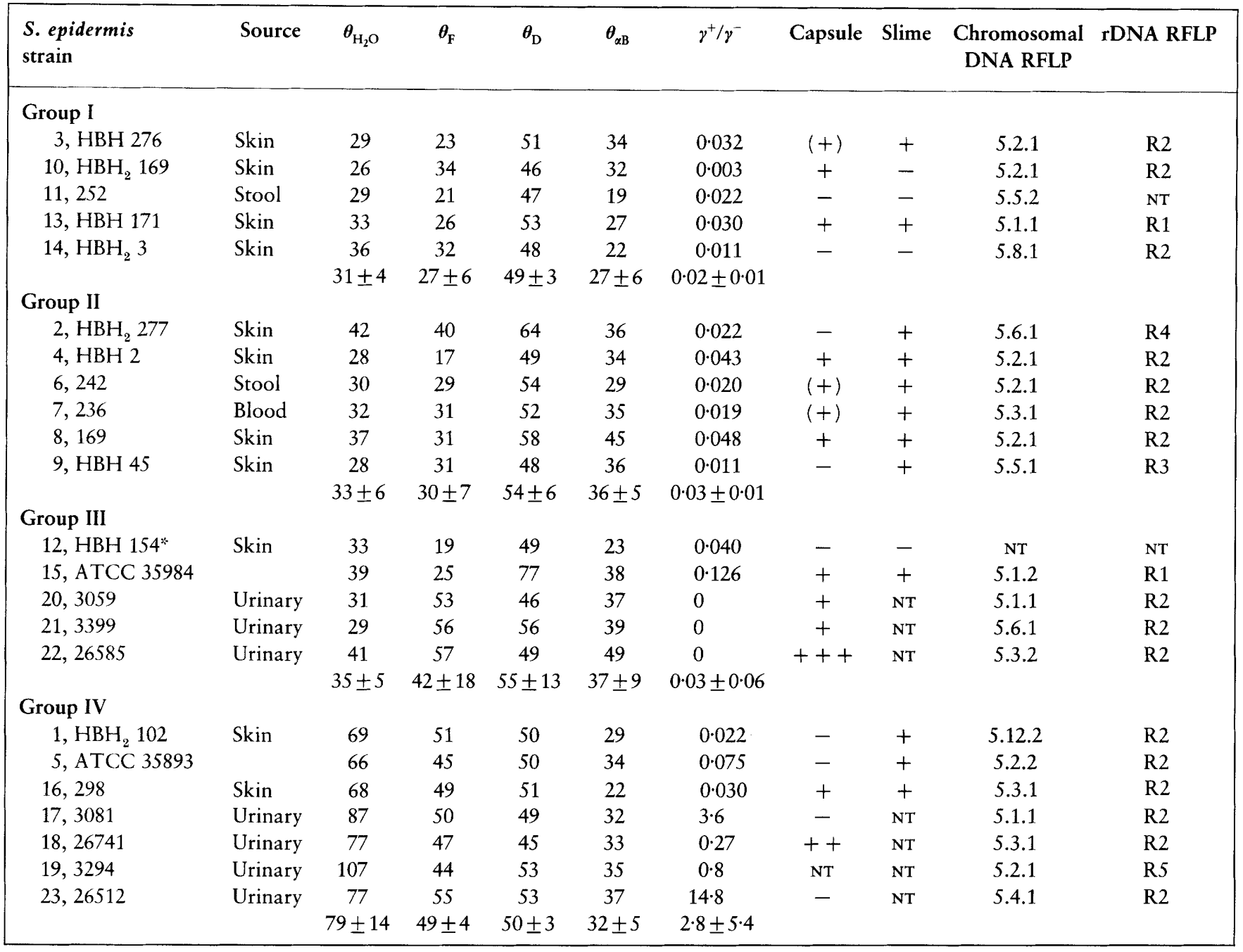

*This strain was later identified as Staphylococcus haemolyticus.

set to a $\mathrm{pH}$ of $2,3,4,5,7$ or 9 using either $\mathrm{HCl}$ or $\mathrm{KOH}$, to a density of approximately $1 \times 10^{7}$ cells $\mathrm{ml}^{-1}$. The electrophoretic mobility at $150 \mathrm{~V}$ of the resuspended bacteria was then measured using a Lazer Zee Meter 501 (PenKem) which uses the scattering of incident laser light to detect the bacteria. The mobility of the bacteria under the applied voltage was converted to the zeta potential using the HelmholtzSmoluchowski equation (Hiemenz, 1977).

Contact angle measurements were determined using a technique described by Busscher et al. (1984) and originally developed by Van Oss \& Gillman (1972). Briefly, each staphylococcal strain was layered onto a $0.45 \mu \mathrm{m}$ pore size filter (Millipore) using negative pressure. The filters were left to air dry at room temperature and humidity until so-called plateau water contact angles could be measured (approx. 1-3 h). For each strain, three independently grown cultures were used, from which two filters of each were prepared and measured. The contact angles, made by sessile droplets of water, formamide, methyleneiodide or $\alpha$-bromonaphthalene on the bacterial layers, were measured using an automated contour monitor. As calculating surface free energies from measured contact angles (Bellon-Fontaine et al., 1990) is still a highly controversial issue in colloid and surface science, we chose to present only the contact angles and not to derive surface free energies. However, based on the analysis proposed by Van Oss et al. (1986), the contact angles measured were employed to obtain an indication of the acid-base character of the cell surfaces, presented here as the ratio between the hydrogen-donating and hydrogen-accepting components of the surface free energies of the staphylococcal cell surface.

The washed pellets were transferred to stainless steel troughs, frozen in liquid nitrogen and subsequently freeze-dried in a Leybold Hereaus Combitron CM30 freeze drier. The freezedried samples, three samples from separate cultures of each 


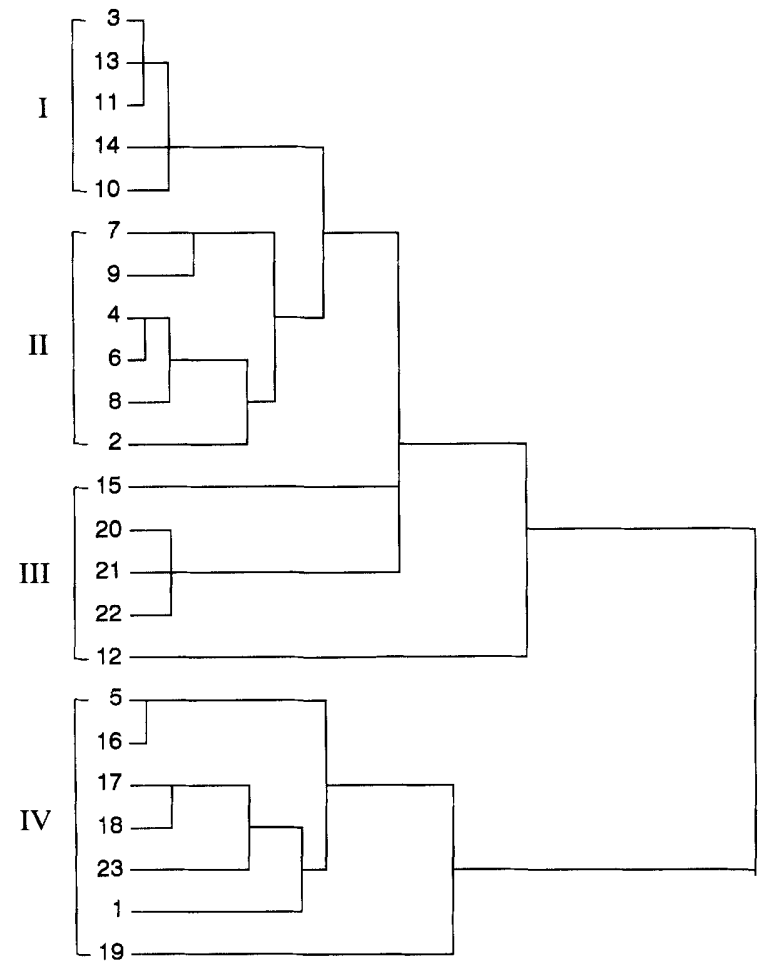

Fig. 1. Dendrogram constructed by a hierarchical cluster analysis on the basis of all measured physico-chemical cell surface properties, including the MATH hydrophobicity of the $S$. epidermidis strains involved in this study. The numbers correspond with the strain code numbers in Table 1.

strain, were pressed into small stainless steel cups, put into the XPS chamber (Surface Science Instruments) and analysed as described by Rouxhet \& Genet (1991). X-Ray production $(10 \mathrm{kV}, 22 \mathrm{~mA})$ at a spot size of $250 \times 1000 \mu \mathrm{m}$ occurred using a magnesium anode. Scans were made of the overall spectrum in the binding energy range of $1-1200 \mathrm{eV}$ at low resolution (pass energy $150 \mathrm{eV}$ ), then peaks over a $20 \mathrm{eV}$ binding energy range were recorded at high resolution (pass energy $50 \mathrm{eV}$ ) for $\mathrm{C}_{1 \mathrm{~s}}, \mathrm{O}_{1 \mathrm{~s}}, \mathrm{~N}_{1 \mathrm{~s}}, \mathrm{P}_{2 \mathrm{p}}$ and $\mathrm{C}_{1 \mathrm{~s}}$ again to account for contamination or deterioration of the samples under $\mathrm{X}$-rays. The area under each peak, after Shirley background subtraction, was used to calculate peak intensities, yielding elemental surface concentration ratios for nitrogen, oxygen and phosphorus to carbon, after correction with sensitivity factors provided by the manufacturer.

Microbial adhesion to hydrocarbon (hexadecane) (MATH). MATH in its so-called kinetic mode (Rosenberg et al., 1980; Lichtenberg et al., 1985) was employed to determine whether the physico-chemical surface properties measured had any effect on the actual adhesion of the staphylococcal strains to an ideally smooth and homogeneous hydrophobic substratum. Briefly, the bacteria were resuspended in $3 \mathrm{ml} 10 \mathrm{mM}$ potassium phosphate solutions, set to $\mathrm{pH} 2,3,4,5,7$ or 9 with $\mathrm{HCl}$ or $\mathrm{KOH}$, to an $\mathrm{OD}_{600}\left(\mathrm{OD}_{0}\right)$ of between $0 \cdot 4$ and $0 \cdot 6$. To the suspension, $150 \mu l$ hexadecane (Merck) was added. The suspensions were vortexed for $10 \mathrm{~s}$ and subsequently left to stand for $10 \mathrm{~min}$ to allow separation of layers, at which time the $\mathrm{OD}_{600}\left(\mathrm{OD}_{\mathrm{t}}\right)$ was again measured. Vortexing and measuring were repeated until the total vortexing time was 60 s. $\log \left(\mathrm{OD}_{\mathrm{t}} / \mathrm{OD}_{0} \times 100\right)$ was plotted against the vortexing time, which, after linear least-squares fitting, yielded the initial removal rate $\left(R_{0}\right)$ as a measure of MATH. MATH was performed at various $\mathrm{pH}$ values so that a determination of the degree of involvement of electrostatic interactions in the adhesion process could be achieved (Busscher et al., 1995; Van der Mei et al., 1995).

Statistical analysis. A hierarchical cluster analysis based on squared Euclidean distances (Ten Bosch et al., 1991) was carried out using all cell surface properties measured as input. Adhesion to hexadecane was included as input because the MATH test is still frequently considered to be an assay probing microbial cell surface hydrophobicity rather than an adhesion assay which, strictly speaking, it is. Statistical analyses were done with the SPSS/PC + statistical program package. All physico-chemical cell surface properties were used as measured, except the N/C, O/C and P/C elemental surface concentration ratios which were multiplied by 500 , 100 and 1000 , respectively, and the initial removal rates which were multiplied by 50 to get them on a similar absolute scale as the other variables. The output of the cluster analysis was presented as a dendrogram, in which strains possessing great similarity were combined at small distances and unlike strains remained separate up to larger distances.

Silicone rubber and plasma. A silastic medical grade silicone rubber (Q7-4750, Nusil) kit was purchased and plates were produced following the procedures suggested by the manufacturer. Briefly, equal proportions of part A and part B were thoroughly blended together and injected into a mould at room temperature through a $3 \mathrm{~mm}$ diameter opening with a force of 3 tons. The silicone rubber was immediately cured at $200{ }^{\circ} \mathrm{C}$ for $50 \mathrm{~min}$. Finally, samples were cleaned in a $2 \%$ RBS detergent solution under simultaneous sonication and thoroughly rinsed in demineralized water, methanol, again with demineralized water and finally with Millipore water.

A $10 \%$ dilution of pooled human plasma in PBS, anticoagulated with sodium citrate, was used for coating the silicone rubber.

Flow chamber, deposition protocol and image analysis. The parallel plate flow chamber $(1 \times \mathrm{w} \times \mathrm{h}=7.6 \times 3.8 \times 0.06 \mathrm{~cm})$ and image analysis system have been described in detail by Sjollema et al. (1989). Prior to each experiment, all tubes and the flow chamber were filled with buffer. Care was taken to remove air bubbles from the system. Flasks containing a staphylococcal suspension $\left(3 \times 10^{8}\right.$ cells $\left.\mathrm{ml}^{-1}\right)$, buffer and plasma, when appropriate, were connected to the flow chamber. All fluids circulated through the chamber under the influence of hydrostatic pressure at a shear rate of $10 \mathrm{~s}^{-1}$ (flow rate $0.025 \mathrm{ml} \mathrm{s}^{-1}$ ). Images were taken from the bottom plate $(5.8 \times 3.8 \mathrm{~cm})$ of the parallel plate flow chamber which consisted of a thin sheet $(0.5 \mathrm{~mm})$ of silicone rubber affixed to a thicker $(1.5 \mathrm{~mm})$ perspex plate. The top plate of the chamber was made of glass.

First, when appropriate, flow was switched to plasma for $1.5 \mathrm{~h}$ to create a conditioning film. Thereafter, flow was switched for $30 \mathrm{~min}$ to buffer for removal of all remnants of plasma from the tubes and chamber, and then to the bacterial suspension which was circulated through the system for $4 \mathrm{~h}$.

The flow chamber was positioned on the stage of a phase contrast microscope (Olympus $\mathrm{BH}-2$ ) equipped with a $\times 40$ ultra long working distance objective (Olympus ULWD-CD Plan $40 \mathrm{PL}$ ). The numbers of bacteria adhering to the silicone rubber over time were observed over a surface area of $0.017 \mathrm{~mm}^{2}$ with a CCD-MX camera (High Technology) mounted on the microscope and enumerated with the aid of image analysis routines (Busscher \& Van der Mei, 1995). The initial increase in the number of adhering micro-organisms 



Fig. 2. Zeta potentials as a function of $\mathrm{pH}$ for $S$. epidermidis strains resuspended in $10 \mathrm{mM}$ potassium phosphate solutions. All data points are results of at least two experiments with separate cultures, results of which coincided within a mean of $2 \mathrm{mV}$. Group I: 3 ( $\square$ ), 13 (A), 11 (O), $14(0), 10$

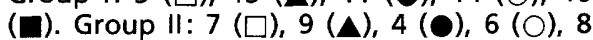
(घ), $2(\triangle)$. Group III: $15(\square), 20(\Delta), 21(0)$,

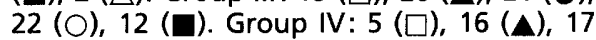
(๑), $18(0), 23(\mathbb{G}), 1(\triangle), 19(*)$. with time, was expressed in a so-called initial deposition rate, $j_{0}\left(\mathrm{~cm}^{-2} \mathrm{~s}^{-1}\right)$, i.e. the number of micro-organisms adhering per unit area with time.

After the experimental period, the flow chamber was emptied by hydrostatic pressure, so that a liquid-air interface could pass over the surface and the numbers of adhering staphylococci withstanding this extremely high removal force (Leenaars \& O'Brien, 1989) were counted as a measure of the adhesive force.

All experiments were performed in triplicate with separate bacterial cultures at room temperature.

\section{RESULTS}

Fig. 1 presents the results of the hierarchical cluster analysis. The dendrogram presented was based on all input data and shows one group, group IV, comprising seven staphylococcal strains, that is well separated from the other strains. This separation is based predominantly on the water and formamide contact angles measured as group IV is integrated completely within the other groups when water and formamide contact angles are omitted from the analysis. Although other groups, comprising five or six strains, can be distinguished in this dendrogram, it is emphasized that these groups are separated by considerably smaller distances.

The groups are further specified in Fig. 2, summarizing the $\mathrm{pH}$ dependence of the zeta potentials of the individual strains in each group. All staphylococcal strains have negative zeta potentials over the entire $\mathrm{pH}$ range, except $S$. epidermidis 3081 which has an isoelectric point at $\mathrm{pH} 2$. Variations between strains mainly involve the absolute value of the zeta potentials and their rate of increase towards positive values at lower $\mathrm{pH}$, but appear unrelated to the grouping given in Fig. 1.

Table 1 lists the contact angles measured for each strain together with an indication of the acid/base character of the cell surfaces and whether or not the strains are capsulated or slime producing. It can be seen that group IV staphylococci (see Fig. 1) are characterized by high water and formamide contact angles, but there is no 
Table 2. Elemental surface concentration ratios measured by XPS of the staphylococcal strains studied and grouped as determined by the cluster analysis as shown in Fig. 1

The SD over three separate bacterial cultures amounted to a mean of $15 \%$.

\begin{tabular}{|c|c|c|c|}
\hline Strain & $\mathrm{N} / \mathrm{C}$ & $\mathrm{O} / \mathrm{C}$ & $\mathrm{P} / \mathrm{C}$ \\
\hline \multicolumn{4}{|c|}{ Group I } \\
\hline 3 & $0 \cdot 131$ & 0.595 & 0.039 \\
\hline 10 & $0 \cdot 129$ & 0.578 & 0.042 \\
\hline 11 & $0 \cdot 124$ & 0.577 & $0 \cdot 040$ \\
\hline 13 & $0 \cdot 123$ & $0 \cdot 604$ & $0 \cdot 041$ \\
\hline \multirow[t]{2}{*}{14} & $0 \cdot 127$ & $0 \cdot 478$ & $0 \cdot 032$ \\
\hline & $0 \cdot 13 \pm 0 \cdot 01$ & $0.57 \pm 0.05$ & $0.04 \pm 0.001$ \\
\hline \multicolumn{4}{|c|}{ Group II } \\
\hline 2 & $0 \cdot 129$ & 0.585 & 0.039 \\
\hline 4 & $0 \cdot 115$ & 0.493 & 0.026 \\
\hline 6 & $0 \cdot 123$ & 0.524 & 0.022 \\
\hline 7 & $0 \cdot 148$ & 0.518 & 0.035 \\
\hline 8 & $0 \cdot 116$ & 0.521 & 0.022 \\
\hline \multirow[t]{2}{*}{9} & $0 \cdot 098$ & 0.483 & $0 \cdot 034$ \\
\hline & $0.12 \pm 0.02$ & $0.52 \pm 0.04$ & $0.03 \pm 0.01$ \\
\hline \multicolumn{4}{|c|}{ Group III } \\
\hline 12 & $0 \cdot 181$ & 0.479 & $0 \cdot 032$ \\
\hline 15 & $0 \cdot 147$ & 0.552 & 0.048 \\
\hline 20 & $0 \cdot 154$ & 0.574 & $0 \cdot 050$ \\
\hline 21 & $0 \cdot 153$ & 0.584 & 0.037 \\
\hline \multirow[t]{2}{*}{22} & $0 \cdot 150$ & $0 \cdot 513$ & $0 \cdot 031$ \\
\hline & $0 \cdot 16 \pm 0 \cdot 01$ & $0.54 \pm 0.04$ & $0.04 \pm 0.01$ \\
\hline \multicolumn{4}{|c|}{ Group IV } \\
\hline 1 & $0 \cdot 154$ & $0 \cdot 561$ & $0 \cdot 034$ \\
\hline 5 & $0 \cdot 137$ & 0.555 & 0.039 \\
\hline 16 & $0 \cdot 145$ & 0.561 & $0 \cdot 036$ \\
\hline 17 & $0 \cdot 145$ & $0 \cdot 461$ & 0.026 \\
\hline 18 & $0 \cdot 150$ & 0.468 & $0 \cdot 030$ \\
\hline 19 & $0 \cdot 123$ & $0 \cdot 367$ & $0 \cdot 028$ \\
\hline \multirow[t]{2}{*}{23} & $0 \cdot 149$ & 0.595 & $0 \cdot 046$ \\
\hline & $0 \cdot 14 \pm 0 \cdot 01$ & $0.51 \pm 0.08$ & $0.03 \pm 0.01$ \\
\hline
\end{tabular}

connection between any of the other groups and encapsulation or slime production. As a consequence of the high water and formamide contact angles of group IV staphylococci, the ratio between the hydrogendonating and electron-donating surface free energy parameters in Table 1 are much higher than observed for the other groups and it can be expected that the group IV staphylococci have a more acidic surface than representatives of the other groups. The molecular characterization of strains is given in Table 1 as well. Neither chromosomal nor ribosomal typing shows any relationship with physico-chemical characteristics.

Table 2 summarizes the elemental surface compositions, as shown by XPS, of the strains. All strains have a high $\mathrm{O} / \mathrm{C}$ elemental surface composition ratio with a sizeable $\mathrm{P} / \mathrm{C}$ ratio. Group III and IV staphylococci are higher in nitrogen content.
The initial removal rates of the strains by hexadecane in MATH are given in Fig. 3 as a function of $\mathrm{pH}$. The highest removal rates for all strains were observed at $\mathrm{pH} 2$. Removal rates decreased strongly with increasing $\mathrm{pH}$, concurrent with the microbial zeta potentials becoming more negative. Group I staphylococci showed the least $\mathrm{pH}$ dependence of their removal rates, possibly caused by a smaller $\mathrm{pH}$ dependence of their zeta potentials. In contrast, group IV staphylococci demonstrated the strongest $\mathrm{pH}$ dependence of their removal rates.

Subsequently, six staphylococcal strains were selected, based on their cell surface properties, for adhesion studies in the parallel plate flow chamber. Fig. 4 is an example of the deposition kinetics of one such strain, $S$. epidermidis 242, to silicone rubber with and without adsorbed plasma proteins. The presence of a conditioning film on the silicone rubber had a reducing effect on the adhesion of this strain, as for all other strains studied. This can be seen clearly in Table 3, summarizing the deposition data of the six strains selected to silicone rubber with and without a conditioning film. Note that in general more than $60 \%$ of the adhering staphylococci are stimulated to detach by the passage of a liquid-air interface over the adhering cells irrespective of the presence or absence of a conditioning film on the silicone rubber.

\section{DISCUSSION}

In this paper, $23 \mathrm{~S}$. epidermidis strains were grouped according to their phenotypic appearance by physicochemical cell surface properties. A hierarchical cluster analysis revealed four distinct groups, of which one was well separated from the other three. The distinction of group IV staphylococci was based predominantly on their water and formamide contact angles and did not relate to the absence or presence of a capsule or slime production. A genotypic characterization of the present collection of staphylococci does not bear any relation to the grouping obtained in this study based on the physicochemical appearance of the micro-organisms.

Previously we have done a similar grouping on a collection of 48 widely varying bacterial strains (Ten Bosch et al., 1991), including oral streptococci, staphylococci, Escherichia coli, Acinetobacter calcoaceticus and Serratia marcescens strains and found that the staphylococci, Streptococcus mitis and Streptococcus rattus formed separate groups. Grouping of more related mutans streptococci, comprising 15 strains in total (Van der Mei et al., 1991), only separated Streptococcus rattus strains from the other mutans streptococci included (Streptococcus mutans, Streptococcus cricetus and Streptococcus sobrinus) on the basis of low water contact angles, highly negative zeta potentials and high $\mathrm{O} / \mathrm{C}$ and $\mathrm{P} / \mathrm{C}$ elemental surface concentration ratios. Four genotypically characterized Lactobacillus species, comprising 27 strains (Millsap et al., 1997), were grouped recently by phenotypic, physico-chemical cell surface properties. One well separated group was 

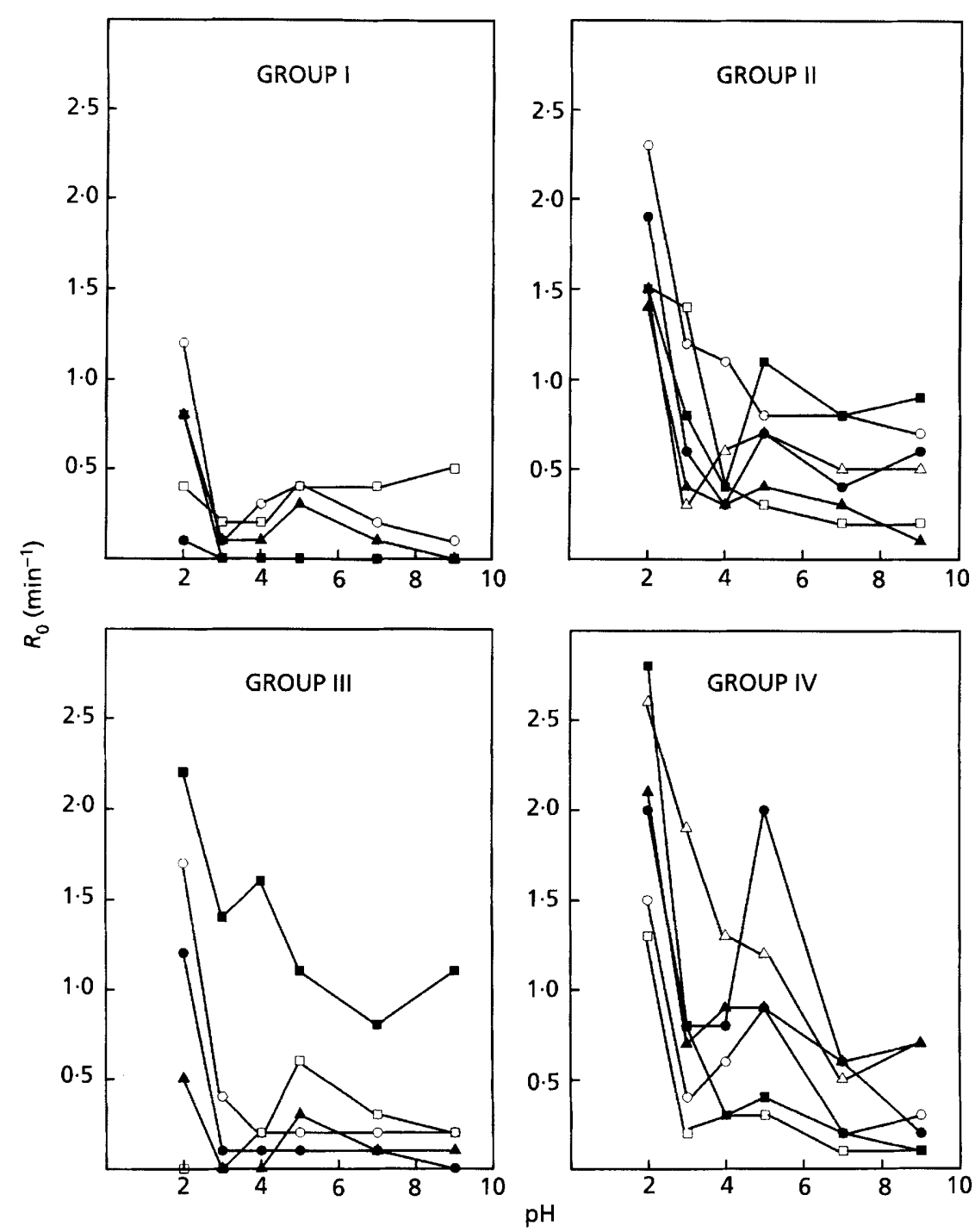

Fig. 3. Initial removal rates, $R_{0}$ by hexadecane of $S$. epidermidis strains resuspended in $10 \mathrm{mM}$ potassium phosphate solutions as a function of $\mathrm{pH}$. All data points are results of at least two experiments with separate cultures, the results of which coincided within a mean of $20 \%$. Group I: 3 $(\square), 13(\Delta), 11(0), 14(O), 10(\square)$. Group II: $7(\square), 9(\Delta), 4(O), 6(\bigcirc), 8(\square), 2(\triangle)$. Group III: $15(\square), 20(\Delta), 21(\bullet), 22(0), 12$ (D). Group IV: $5(\square), 16(\Delta), 17(0), 18(0)$, $23(\square), 1(\triangle), 19$ (*).

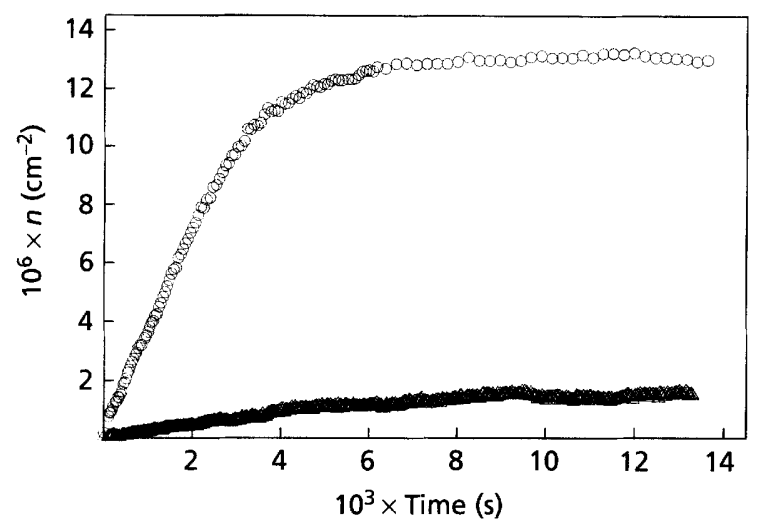

Fig. 4. Example of the deposition kinetics of $S$. epidermidis 242 to silicone rubber with $(\triangle)$ and without $(O)$ a $10 \%$ plasma coating. obtained for Lactobacillus acidophilus strains, based on the cell surface hydrophobicity and isoelectric point, but other Lactobacillus strains, including Lactobacillus casei, Lactobacillus fermentum and Lactobacillus plantarum, were divided over various heterogeneous groups. Considering that the above studies comprise 90 strains in total, divided over 19 species, while none of them show a ubiquitous relation between phenotypic appearance of the organisms and taxonomic nomenclature or genotyping using a single restriction enzyme RFLP pattern, it is proposed that the phenotypic appearance of strains is mostly controlled by environmental conditions.

The group IV staphylococcal cell surface contains a high number of hydrogen-donating cell surface components, that we could not identify by XPS. This might be due to collapse of cell surface components during freeze-drying for XPS (Van der Mei \& Busscher, 1990) or the surface insensitivity of XPS as compared to the contact angle technique (Van der Mei et al., 1991). Van Oss et al. 
Table 3. Initial adhesion [initial deposition rates $\left(j_{0}\right)$ and adhering numbers in a stationary end-point $\left.\left(n_{s}\right)\right]$ of six $S$. epidermidis strains to silicone rubber with $(+)$ and without $(-)$ adsorbed plasma proteins in a parallel plate flow chamber

Experiments were carried out in duplicate with separately cultured bacteria and coincided within $15 \%$.

\begin{tabular}{|c|c|c|c|c|c|c|}
\hline \multirow[t]{3}{*}{ Strain } & \multicolumn{2}{|c|}{$j_{0}\left(\mathrm{~cm}^{-2} \mathrm{~s}^{-1}\right)$} & \multicolumn{2}{|c|}{$10^{6} \times n_{s}\left(\mathrm{~cm}^{-2}\right)$} & \multicolumn{2}{|c|}{$\begin{array}{l}\text { Percentage } \\
\text { detachment }\end{array}$} \\
\hline & \multirow{2}{*}{-} & \multirow{2}{*}{+} & \multirow{2}{*}{ - } & \multirow{2}{*}{+} & & - \\
\hline & & & & & - & + \\
\hline \multicolumn{7}{|c|}{ Group I } \\
\hline 10 & 1970 & 64 & $15 \cdot 0$ & $0 \cdot 3$ & 98 & 88 \\
\hline \multicolumn{7}{|c|}{ Group II } \\
\hline 6 & 3429 & 197 & $16 \cdot 2$ & $1 \cdot 6$ & 72 & 83 \\
\hline 7 & 1360 & 318 & $11 \cdot 2$ & $3 \cdot 4$ & 58 & 88 \\
\hline \multicolumn{7}{|c|}{ Group III } \\
\hline 21 & 2127 & 346 & $13 \cdot 4$ & $2 \cdot 1$ & 70 & 74 \\
\hline \multicolumn{7}{|c|}{ Group IV } \\
\hline 1 & 3872 & 246 & $14 \cdot 5$ & $6 \cdot 5$ & 57 & 85 \\
\hline 19 & 1958 & 121 & $11 \cdot 5$ & $1 \cdot 0$ & 77 & 60 \\
\hline
\end{tabular}

*Percentage detachment denotes the percentage of adhering staphylococci stimulated to detach upon the passage of an airbubble through the flow chamber.

(1997) suggested that staphylococcal cell surfaces with a high hydrogen-donating cell surface free energy parameter are capsulated. In this study we did not find a relationship between encapsulation and the hydrogendonating cell surface free energy parameter (see Table 1), but it is emphasized that the detection of capsules by Indian ink as done here and in many other studies (Matthews et al., 1991) may not be adequate in all cases. A possible conclusion is that the contact angles must be considered superior for these purposes, owing to their extreme surface sensitivity.

The ideally smooth and homogeneous hexadecane surfaces in MATH make this method suitable to demonstrate the importance of physico-chemical cell surface properties in adhesion, despite the fact that mass transport conditions in MATH are uncontrolled and the test does not resemble real-life conditions like those of the flow chamber experiments. The hexadecane surface in MATH is not only hydrophobic, but also charged and its zeta potential is negative down to $\mathrm{pH} 2-3$, below which the zeta potential of hexadecane is virtually zero. The staphylococci in this study also have a considerable negative charge (see Fig. 2). Hence, the DLVO theory of colloidal stability (Rutter \& Vincent, 1980) predicts electrostatic repulsion between the hexadecane droplets in MATH and the staphylococci that has to be overcome by attractive Lifshitz-Van der Waals forces for adhesion to occur. The electrostatic interaction energy between

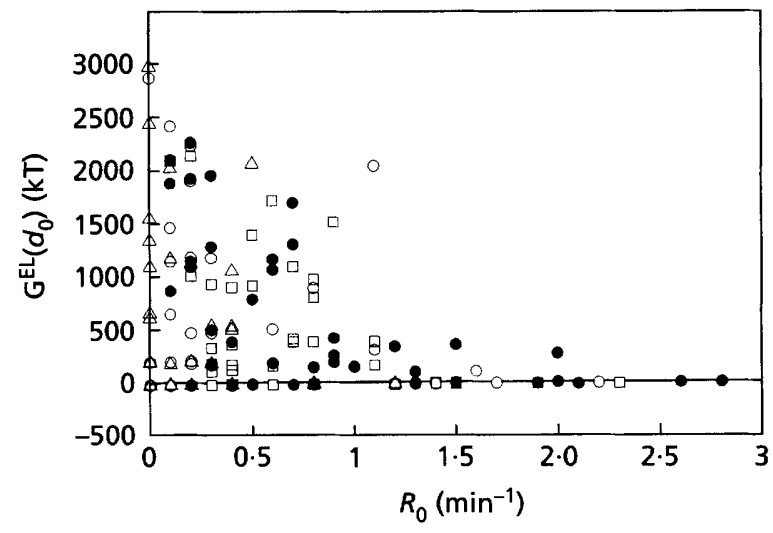

Fig. 5. The electrostatic interaction energy, $G^{\mathrm{EL}}\left(d_{0}\right)$, between hexadecane droplets and CNS strains as a function of the removal rate $R_{0}$ by hexadecane in a $10 \mathrm{mM}$ potassium phosphate solution in MATH, calculated for the minimal separation distance, $d_{0}$, of $0.157 \mathrm{~nm} . \triangle$, group I; $\square$, group II; O. group III; 0 , group IV.

two spheres can be calculated according to:

$$
\begin{array}{r}
\Delta G^{\mathrm{EL}}(d)=\frac{\pi \varepsilon a_{1} a_{2}\left(\zeta_{1}^{2}+\zeta_{2}^{2}\right)}{\left(a_{1}+a_{2}\right)}\left[\frac{2 \zeta_{1} \zeta_{2}}{\zeta_{1}^{2}+\zeta_{2}^{2}} \ln \frac{1+\exp (-\kappa d)}{1-\exp (-\kappa d)}\right. \\
+\ln \{1-\exp (2 \kappa d)\}]
\end{array}
$$

in which $\varepsilon$ denotes the permittivity of the medium, $a_{1}$ and $a_{2}$ the radii of the bacterium and hexadecane droplet, respectively, $\zeta$ the zeta potential, $\kappa$, the double layer thickness and $d$ the separation distance. Fig. 5 presents the electrostatic interaction energy, $\Delta G^{\mathrm{EL}}\left(d_{0}\right)$, according to equation ( 1 ) and for the experimental conditions of our MATH test as a function of the initial removal rates of the staphylococci by hexadecane. When the electrostatic repulsive interaction energy at closest approach $\left(d_{0}=0.157 \mathrm{~nm}\right)$ exceeds $500 \mathrm{kT}$, significant removal $\left(>1.0 \mathrm{~min}^{-1}\right)$ by hexadecane is impeded by lack of sufficiently strong attractive forces. Significant removal only occurs when the electrostatic repulsion is less than $500 \mathrm{kT}$. However, the absence of strong electrostatic repulsion alone is not the only condition to be fulfilled for adhesion to occur and attractive LifshitzVan der Waals forces, of which cell surface hydrophobicity is a corollary, must be operative as well (see Fig. 5 and Table 1). Similar analyses have been done by us for a collection of oral (Van der Mei \& Busscher, 1996; Geertsema-Doornbusch et al., 1993) and thermophilic dairy (Van der Mei et al., 1993) streptococci.

Conditions for adhesion studies more similar to real life can be obtained in a parallel plate flow chamber. Because the use of a parallel plate flow chamber is much more time-consuming than MATH, six representatives of the groups distinguished were selected for experiments in the parallel plate flow chamber. The degree of complexity of adhesion to silicone rubber with a similar hydrophobicity and negative charge to hexadecane becomes immediately obvious from Table 3 . Neither the 
initial deposition rates, nor the stationary end-point adhesion, nor the percentage detachment of adhering staphylococci by air-bubble passage show any relationship with group division (see Fig. 1), intrinsic cell surface hydrophobicity (see Table 1) or zeta potentials (see Fig. 2 ). This seems to be a frustrating aspect of staphylococcal research which is in sharp contrast with our experiences with peritrichously fibrillated oral streptococci. Adhesion of these streptococcal strains to various artificial substrata in a stationary end-point related well with surface thermodynamic predictions based on contact angles, while the kinetics of streptococcal adhesion appeared governed by electrostatic interactions. The massive detachment of adhering staphylococci from silicone rubber upon the passage of an air-bubble through the flow chambers indicates a low affinity of these predominantly hydrophilic organisms for a hydrophobic substratum, which is in accordance with surface thermodynamics. As staphylococci behave as expected on the basis of physico-chemistry when adhering to a chemically homogeneous surface like that of hexadecane, it is suggested that the chemical complexity of staphylococcal cell surfaces in contact with an inevitably heterogeneous real-life surface will be much greater than for streptococcal cell surfaces.

The presence of a conditioning film of adsorbed plasma proteins on the silicone rubber not only slows down the deposition kinetics of the staphylococci (Table 3), but also the stationary end-point adhesion is greatly reduced. Proteins that adsorb from plasma are predominantly albumin, fibrinogen and immunoglobulin G. Albumin usually adsorbs initially and may become displaced over time by fibrinogen and immunoglobulin G. Siverhus et al. (1990) studied the influence of adsorbed albumin to Dacron vascular prostheses on staphylococcal adhesion and found that albumin adsorption does not increase CNS adhesion. Cheung \& Fischetti (1990) observed that staphylococcal adhesion to fibrinogen-coated catheters was blocked by goat anti-human fibrinogen antibody, but not fibronectin, vitronectin or non-immune goat IgG. Consequently, it was concluded that fibrinogen is the dominant plasma mediator of staphylococcal adhesion. This is in line with a study by Elwing \& Askendal (1994) using a 'lens-on-surface method' for investigating adhesion of Staphylococcus aureus to substrata incubated in blood plasma. In their experiments, adhesion coincided with adsorbed fibrinogen or IgG at the surface. Considering the time-scale of albumin displacement and the hydrophobicity of silicone rubber, it is likely that under our conditions the conditioning film consists mainly of albumin. Hence, we conclude that adsorbed albumin reduces staphylococcal adhesion compared to adhesion to uncoated silicone rubber.

In summary, this study demonstrates that $S$. epidermidis strains can be divided into at least four phenotypically different groups on the basis of their physico-chemical cell surface properties. The physico-chemical cell surface properties, most notably the zeta potentials, govern, in part, staphylococcal adhesion in an artificial adhesion set-up to an ideally smooth and chemically homogeneous substratum. Adhesion to a less ideal real-life surface, like silicone rubber, appears more complex. Adsorbed plasma proteins reduced staphylococcal adhesion. This data makes it much more difficult to develop biomaterial surfaces capable of resisting colonization by potentially pathogenic CNS.

\section{ACKNOWLEDGEMENTS}

We are greatly indebted to Mrs Marjon Schakenraad-Dolfing and Mrs Ellen van Drooge for manuscript preparation.

\section{REFERENCES}

Bellon-Fontaine, M. N., Mozes, N., Van der Mei, H. C., Sjollema, J., Cerf, O., Rouxhet, P. G. \& Busscher, H. J. (1990). A comparison of thermodynamic approaches to predict the adhesion of dairy microorganisms to solid substrata. Cell Biophysics 17, 93-106.

Bialkowska-Hobrzanska, H., Harry, V., Jaskot, D. \& Hammerberg, O. (1990a). Typing of coagulase-negative staphylococci by Southern hybridization of chromosomal DNA fingerprints using an rRNA gene probe. Eur J Clin Microbiol Infect Dis 9, 588-594.

Bialkowska-Hobrzanska, H., Jaskot, D. \& Hammerberg, 0. (1990b). Evaluation of restriction endonuclease fingerprinting of chromosomal DNA and plasmid profile analysis for characterization of multiresistant coagulase-negative staphylococci in bacteraemic neonates. J Clin Microbiol 28, 269-275.

Bialkowska-Hobrzanska, H., Jaskot, D. \& Hammerberg, O. (1993). Molecular characterization of the coagulase-negative staphylococcal surface flora of premature neonates. J Gen Microbiol 139, 2939-2944.

Boswald, M., Girisch, M., Greil, J., Spies, T., Stehr, K., Krall, T. \& Guggenbichler, J.P. (1995). Antimicrobial activity and biocompatibility of polyurethane and silicone catheters containing low concentrations of silver: a new perspective in prevention of polymer associated foreign body infections. Zentralbl Bakteriol 283, 187-200.

Busscher, H. J. \& Van der Mei, H. C. (1995). Use of flow chamber devices and image analysis methods to study microbial adhesion. Methods Enzymol 253, 455-477.

Busscher, H. J., Weerkamp, A. H., Van der Mei, H. C., Van Pelt, A. W. J., De Jong, H. P. \& Arends, J. (1984). Measurement of the surface free energy of bacterial cell surfaces and its relevance for adhesion. Appl Environ Microbiol 48, 980-983.

Busscher, H. J., Cowan, M. M. \& Van der Mei, H. C. (1992). On the relative importance of specific and non-specific approaches to oral microbial adhesion. FEMS Microbiol Rev 88, 199-210.

Busscher, H. J., Bialkowska-Hobrzanska, H., Reid, G., Van der Kuyl-Booy, M. \& Van der Mei, H. C. (1994). Physico-chemical characteristics of two pairs of coagulase-negative staphylococcal isolates with different plasmid profiles. Colloids Surf B: Biointerfaces 2, 73-82.

Busscher, H. J., Van de Belt-Gritter, B. \& Van der Mei, H. C. (1995). Implications of microbial adhesion to hydrocarbons for evaluating cell surface hydrophobicity. 1. Zeta potentials of hydrocarbon droplets. Colloids Surf B: Biointerfaces 5, 111-116.

Busscher, H. J., Geertsema-Doornbusch, G. I. \& Van der Mei, H. C. (1997). Adhesion to silicone rubber of yeasts and bacteria isolated from voice prostheses: influence of salivary conditioning films. J Biomed Mater Res 34, 201-210.

Cheung, A. L. \& Fischetti, V. A. (1990). The role of fibrinogen in 
staphylococcal adherence to catheters in vitro. J Infect Dis 161, 1177-1186.

Cheung, A. L., Krishnan, M., Jaffe, E. A. \& Fischetti, V. A. (1991). Fibrinogen acts as a bridging molecule in the adherence of Staphylococcus aureus to cultured human endothelial cells. J Clin Invest 87, 2236-2245.

Christensen, G. D., Simpson, W. A., Bisno, A. L. \& Beachy, E. H. (1982). Adherence of slime-producing strains of Staphylococcus epidermidis to smooth surfaces. Infect Immun 37, 318-326.

Elwing, H. \& Askendal, A. (1994). Lens-on-method for investigating adhesion of Staphylococcus aureus to solid surfaces incubated in blood plasma. J Biomed Mater Res 28, 775-782.

Elwing, H., Askendal, A. \& Lundström, I. (1987). Competition between adsorbed fibrinogen and high molecular weight kininogen on solid surfaces incubated in human plasma (the Vroman effect) : influence of solid surface wettability. J Biomed Mater Res 21, 1023-1028.

Geertsema-Doornbusch, G. I., Van der Mei, H. C. \& Busscher, H. J. (1993). Microbial cell surface hydrophobicity. The involvement of electrostatic interactions in microbial adhesion to hydrocarbons (MATH). J Microbiol Methods 18, 61-68.

Gilbert, P., Evans, D. J., Duguid, I. G., Evans, E. \& Brown, M. R. W. (1991). Cell surface properties of Escherichia coli and Staphylococcus epidermidis. In Microbial Cell Surface Analysis: Structural and Physicochemical Methods, pp. 339-356. Edited by N. Mozes, P. S. Handley, H. J. Busscher \& P. G. Rouxhet. New York: VCH Publishers.

Gristina, A. G., Naylor, P. \& Myrvik, Q. (1988). Infections from biomaterials and implants: a race for the surface. Med Prog Technol 14, 205-224.

Hiemenz, P. C. (1977). Electrophoresis and other electrokinectic phenomena. In Principles of Colloid and Surface Chemistry, pp. 452-487. Edited by J. J. Lagowski. New York: Marcel Dekker.

Hogt, A. H., Dankert, J., De Vries, J. A. \& Feyen, J. (1983). Adhesion of coagulase-negative staphylococci to biomaterials. J Gen Microbiol 129, 2959-2968.

Lee, H. I., Choi, C. S., Chung, S. I. \& Yang, Y. T. (1995). Antibiotic susceptibilities of slime-forming and non-forming strains of coagulase-negative staphylococci isolated from clinically significant specimens. J Kor Soc Microbiol 30, 403-413.

Leenaars, A. F. M. \& O'Brien, S. B. G. (1989). Particle removal from silicon substrates using surface tension forces. Philips $J$ Res 44, 183-209.

Lichtenberg, D., Rosenberg, M., Sharfman, N. \& Ofek, I. (1985). A kinetic approach to bacterial adherence to hydrocarbon. J Microbiol Methods 4, 141-146.

Matthews, K. R., Oliver, S. P. \& Guidney, A. J. (1991). Encapsulation of coagulase-negative staphylococci of bovine origin. J Appl Bacteriol 71, 38-45.

Millsap, K. W., Reid, G., Van der Mei, H. C. \& Busscher, H. J. (1997). Cluster analysis of genotypically characterized Lactobacillus species based on physico-chemical cell surface properties and relation with their adhesion to hexadecane. Can J Microbiol 43, 284-291.

Rosenberg, M., Gutnick, D. \& Rosenberg, E. (1980). Adherence of bacteria to hydrocarbons: a simple method for measuring cell surface hydrophobicity. FEMS Microbiol Lett 9, 29-33.

Rouxhet, P. G. \& Genet, M. J. (1991). Chemical composition of the microbial cell surface by X-ray photoelectron spectroscopy. In Microbial Cell Surface Analysis: Structural and Physicochemical Methods, pp. 173-220. Edited by N. Mozes, P. S. Handley, H. J. Busscher \& P. G. Rouxhet. New York: VCH Publishers.
Rutter, P. R. \& Vincent, B. (1980). The adhesion of microorganisms to surfaces: physico-chemical aspects. In Microbial Adhesion to Surfaces, pp. 79-91. Edited by R. C. W. Berkeley, J. M. Lynch, J. Melling, P. R. Rutter \& B. Vincent. London: Ellis Horwood.

Siverhus, D. J., Schmitt, D. D., Edmiston, C. E., Bandyk, D. F., Seabrook, G. R., Goheen, M. P. \& Towne, J. B. (1990). Adherence of mucin and non-mucin-producing staphylococci to preclotted and albumin-coated velour knitted vascular grafts. Surgery 107, 613-619.

Sjollema, J., Busscher, H. J. \& Weerkamp, A. H. (1989). Real time enumeration of adhering microorganisms in a parallel plate flow cell using automated image analysis. J Microbiol Methods 9, 73-78.

Ten Bosch, J. J., Van der Mei, H. C. \& Busscher, H. J. (1991). Statistical analyses of bacterial species based on physico-chemical surface properties. Biofouling 4, 141-150.

Van der Mei, H. C. \& Busscher, H. J. (1990). On the difference between water contact angles measured on partly dehydrated and on freeze-dried oral streptococci. J Colloid Interface Sci 136, 297-300.

Van der Mei, H. C. \& Busscher, H. J. (1996). Detection by physicochemical techniques of an amphiphilic surface component on Streptococcus mitis strains involved in non-electrostatic binding to surfaces. Eur J Oral Sci 104, 48-55.

Van der Mei, H. C., Brokke, P., Dankert, J., Feyen, J., Rouxhet, P. G. \& Busscher, H. J. (1989). Physicochemical surface properties of nonencapsulated and encapsulated coagulase-negative staphylococci. Appl Environ Microbiol 55, 2806-2814.

Van der Mei, H. C., De Soet, J. J., De Graaff, J., Rouxhet, P. G. \& Busscher, H. J. (1991). Comparison of the physico-chemical surface properties of Streptococcus rattus with those of other mutans streptococcal species. Caries Res 25, 415-423.

Van der Mei, H. C., De Vries, J. \& Busscher, H. J. (1993). Hydrophobic and electrostatic cell surface properties of thermophilic dairy streptococci. Appl Environ Microbiol 59, 4305-4312.

Van der Mei, H. C., Van de Belt-Gritter, B. \& Busscher, H. J. (1995). Implications of microbial adhesion to hydrocarbons for evaluating cell surface hydrophobicity. 2. Adhesion mechanisms. Colloids Surf B: Biointerfaces 5, 117-126.

Van Oss, C. J. \& Gillman, C. F. (1972). Phagocytosis as a surface phenomenon. I. Contact angles and phagocytosis of nonopsonized bacteria. J Reticuloendothel Soc 12, 283-292.

Van Oss, C. J., Good, R. J. \& Chaudhury, M. K. (1986). The role of Van der Waals forces and hydrogen bonds in 'Hydrophobic Interactions' between biopolymers and low energy surfaces. $J$ Colloid Interface Sci 111, 378-390.

Van Oss, C. J., Giese, R. F. \& Wu, W. (1997). On the predominant electron-donicity of polar solid surfaces. J Adhesion $63,71-88$.

Vroman, L. \& Adams, A. L. (1985). Adsorption of proteins out of plasma and solutions in narrow spaces. $J$ Colloid Interface Sci 111, 391-402.

Zdanowski, Z., Ribbe, E. \& Schalen, C. (1993). Influence of some plasma proteins on in vitro bacterial adherence to PTFE and Dacron vascular prostheses. APMIS 101, 926-932.

Ziats, N. P., Pankowsky, D. A., Tierney, B. P., Ratnoff, O. D. \& Anderson, J. M. (1990). Adsorption of Hageman factor (factor XII) and other human plasma proteins to biomedical polymers. J Lab Clin Med 116, 687-696.

Received 3 June 1997; revised 4 August 1997; accepted 14 August 1997. 